\title{
Oral glutamine supplementation benefits jejunum but not ileum
}

\author{
Paul E Hardy mD, Karen L Madsen PhD, Olin G Thurston mD, Stewart M Hamilton mD, \\ NINGREN CUI MD, RICHARD N FEDORAK MD
}

PE Hardy, KL MAdsen, OG Thurston, SM Hamilton, N CUI, RN FEDORAK. Oral glutamine supplementation benefits jejunum but not ileum. Can J Gastroenterol 1994;8(2):108-114. Glutamine is the primary metabolic fuel of the small intestine. The ability of enteral glutamine to support jejunal architecture and metabolism is well established, but its effect on intestinal absorptive function, especially in the terminal ileum, remains undetermined. The purpose of this study was to develop a functional ileal fluid absorption surgical injury model and to determine if oral glutamine supplementation would be beneficial in accelerating healing and restoring function. The effects of either $1 \mathrm{~cm}$ resection and ileal end-to-end anastomosis or sham laparotomy on rat in vivo fluid absorption at study start (day 0 ), one and two days was investigated. In sham-operated rats, fluid absorption was not altered. In contrast, ileal fluid absorption was significantly reduced at days $0(17.2 \pm 4.8 \mu \mathrm{L} / \mathrm{cm} / \mathrm{h})$ and 1 $(31.4 \pm 13.6 \mu \mathrm{L} / \mathrm{cm} / \mathrm{h})$, but returned to normal by day $2(71.0 \pm 6.2 \mu \mathrm{L} / \mathrm{cm} / \mathrm{h})$ in anastomosed rats. To examine the effects of glutamine in this model, rats were fed either glutamine $(2.4 \mathrm{~g} / \mathrm{kg} /$ day $)$ or an isonitrogenous glycine-supplemented elemental oral diet for five days before their randomization to sham or anastomotic groups. This dose of glutamine reached the ileum and was completely absorbed along the small intestine. Glutamine-fed rats demonstrated no difference in recovery of in vivo ileal fluid absorption, ileal villus morphometric measurements, mg DNA:mg protein ratio, degree of inflammation or glutaminase activity. In contrast, jejunal, but not ileal, villus morphometry, mg DNA:mg protein ratio and glutaminase activity were increased in glutamine-fed 'not operated' rats $(\mathrm{P}<0.01)$, indicating that the jejunum, but not the ileum, responded to the glutamine-supplemented diet. These studies demonstrate that ileal resection and anastomosis causes transient impairments in in vivo fluid absorption, and oral glutamine supplementation offers a beneficial effect to jejunal, but not ileal, intestinal mucosa. These results suggest that the effects of oral glutamine may be limited to the proximal intestine. (Pour résumé, voir page 109)

Key Words: Absorption, Enteral nutrition, Glutamine, Intestine, Transport

Division of Gastroenterology, Department of Medicine, and Department of Surgery, University of Alberta, Edmonton, Alberta

Correspondence: Dr Richard N Fedorak, Division of Gastroenterology, Department of

Medicine, University of Alberta, 519 Robert Newton Research Building, Edmonton, Alberta

T6G 2C2. Telephone (403) 492-6941, Fax (403) 492-3744

Received for publication May 6, 1993. Accepted October 18, 1993
J LUTAMINE IS A NONESSENTIAL amino acid, sufficient quantities of which are synthesized by the body in healthy subjects. During surgical stress or critical illness, however, the body's requirement for glutamine frequently exceeds its production (1-4). As well, glutamine is a preferred energy substrate for small intestinal enterocytes (5-8). Therefore, under the stress of a systemic illness or intestinal injury, enterocytes may be unable to meet their requirements for glutamine as a primary metabolic fuel, and exogenous administration of glutamine may, therefore, be necessary.

While glutamine administration has been shown to improve jejunal morphometric measurements in several animal models of enterocolitis (9-13), the effects of glutamine on ileal morphology and functional absorption have not been well studied. Parenteral glutamine administration has been demonstrated to be safe (14) and beneficial (15) for humans, and it is possible that the enteral route may impart additional positive effects to the intestine. It is, therefore, important to know whether the beneficial jejunal effects of orally administered glutamine also occur in the ileum, and whether these beneficial effects occur during typical surgical anastomotic injury or are limited to occasions of experimentally induced enterocolitis or normal tissue. 


\section{Les suppléments oraux de glutamine : avantageux pour le jéjunum mais non pour l'iléon}

RÉSUMÉ : La glutamine est le principal carburant métabolique du petit intestin. La capacité de la glutamine entérique à supporter l'architecture jéjunale et son métabolisme est bien connue, mais son effet sur la fonction d'absorption intestinale, particulièrement au niveau de l'iléon terminal, reste à déterminer. Le but de cette étude était de mettre au point un modèle fonctionnel d'absorption liquidienne iléale avec lésion chirurgicale et de déterminer si un supplément de glutamine oral pouvait accélérer la cicatrisation et rétablir la fonction. Les effets d'une résection de $1 \mathrm{~cm}$ accompagnée d'anastomose termino-terminale iléale ou d'une laparotomie factice sur l'absorption liquidienne in vivo chez le rat ont été mesurés au début de l'étude (jour 0 ) puis aux jours 1 et 2 . Chez les rats ayant subi une laparotomie factice, l'absorption liquidienne n'a pas été modifiée. Par contre, l'absorption liquidienne iléale a été nettement réduite au jour $0(17,2 \pm 4,8 \mu \mathrm{L} /$ $\mathrm{cm} / \mathrm{h})$ et $1(31,4 \pm 13,6 \mu \mathrm{L} / \mathrm{cm} / \mathrm{h})$, mais est revenue à la normale au jour $2(71,0$ $\pm 6,2 \mu \mathrm{L} / \mathrm{cm} / \mathrm{h}$ ) chez les rats anastomosés. Pour examiner les effets de la glutamine dans ce modèle, des rats ont reçu, soit de la glutamine $(2,4 \mathrm{~g} / \mathrm{kg} / \mathrm{jour})$ ou un régime oral élémentaire iso-azoté enrichi de glycine durant cinq jours avant leur assignation aux groupes qui allaient subir la laparotomie ou l'anastomose. Cette dose de glutamine a atteint l'iléon et a été complètement absorbée le long du petit intestin. Les rats qui ont reçu de la glutamine n'ont montré aucune différence sur le plan de la récupération pour ce qui est de l'absorption liquidienne iléale in vivo, de la mesure morphométrique des villosités iléales, du ratio mg ADN:mg protéines, du degré d'inflammation ou de l'activité glutaminase. Par contre, la morphométrie des villosités jéjunales, le ratio mg ADN:mg protéines et l'activité glutaminase se sont élevés chez les rats qui ont reçu de la glutamine $(P<0,01)$, ce qui donne à penser que le jéjunum a répondu au régime enrichi de glutamine. Ces études démontrent que la résection iléale et l'anastomose provoquent une altération transitoire de l'absorption liquidienne in vivo et que le supplément oral de glutamine offre un avantage pour la muqueuse intestinale jéjunale mais non iléale. Ces résultats donnent à penser que les effets de la glutamine orale peuvent se limiter à l'intestin proximal.

The purpose of this study was to determine whether supplemental oral glutamine would restore ileal intestinal absorptive function and improve morphometric analysis in a surgical injury model (see part I - ileal end-to-end surgical anastomotic model). In addition, we determined whether oral glutamine supplements conferred benefits, as determined by morphometric analysis, on the jejunum and/or the ileum in a nonsurgical model (see part II - nonsurgical model).

\section{ANIMALS AND METHODS}

Animals: Male Sprague-Dawley rats weighing between 230 and $270 \mathrm{~g}$ (Biotron) were used in all experiments. The animals were allowed to become acclimatized to the animal facility for at least $48 \mathrm{~h}$ before entering the study. Animals were housed in individual cages, on a $12 \mathrm{~h}$ light/dark cycle, and allowed water ad libitum.
Chemicals: Glutamine, glycine, alanine, beta-NAD (from yeast, molecular weight 633.4), 2,5- and 3,5-ADP, and glutamic dehydrogenase (type II, from bovine liver in $50 \%$ glycerol) were purchased from Sigma Chemical Co (Missouri). L- ${ }^{14} \mathrm{C}$-glutamine $\left(9.5 \times 10^{4} \mathrm{MBq} /\right.$ $\mathrm{mmol}$ ) was purchased from Amersham. All other chemicals were reagent grade and were purchased from Fisher Scientific.

\section{PART I - ILEAL END-TO-END SURGICAL ANASTOMOTIC MODEL}

Feeding and dietary supplementation: Previously chow-fed animals were randomized to receive either a glutaminesupplemented (treatment group receiving glutamine) or an isonitrogenous glycine-supplemented (untreated group receiving no glutamine) elemental diet. Both groups received the designated diet for five days before experimenta- tion. The diet consisted of powdered vital HN (79 g) (Ross Laboratories) mixed with glutamine $(5.1 \mathrm{~g})$ or glycine powder $(5.1 \mathrm{~g})$; this amount of vital $\mathrm{HN}$-glutamine mix provided a close approximate of the $1 \mathrm{~g} / \mathrm{rat} /$ day (approximate $4 \mathrm{~g} / \mathrm{kg} /$ day) glutamine intake amount used in previous studies (2-8). The powdered diet was provided in containers that prevented spillage or soiling but provided easy access for ad libitum intake. Food containers were weighed and refilled daily to record oral intake accurately and to prevent degradation of nutrients.

Operative procedure: Rats were anesthetized with an intraperitoneal injection of ketamine $(80 \mathrm{mg} / \mathrm{kg})$ and xylazine $(8 \mathrm{mg} / \mathrm{kg})$. Oxygen was given by mask, and a warming lamp was placed over the operative field. The abdomen was shaved and a midline incision made. A single dose of cefazolin $(40 \mathrm{mg} / \mathrm{kg}$ ) was administered into the peritoneal cavity, and a 10 to $15 \mathrm{~cm}$ segment of terminal ileum was isolated. Under $2.5 \mathrm{x}$ magnification, mesenteric vessels were ligated with $6-0$ silk ties on both sides of a $1 \mathrm{~cm}$ segment of ileum, which was then resected. An end-toend anastomosis was initiated over a macaroni stent using interrupted sutures of $6-0$ silk. On completion of half the anastomosis, the stent was removed and the remainder of the anastomosis completed without the stent. Injection of a saline solution to distend mildly the intestinal lumen confirmed a competent anastomosis without leak. The abdomen was then closed. All animals were allowed to recover in an incubator warmed to $37^{\circ} \mathrm{C}$ and were provided with supplemental oxygen. Sham-operated controls underwent an operative procedure that simulated the surgery described above, without the resection and anastomosis.

\section{PART II - NONSURGICAL MODEL}

Feeding and dietary supplementation: To ensure adequate intraluminal ileal concentrations of glutamine in this group, glutamine was administered by

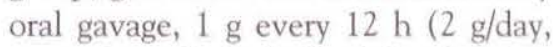
approximately $8 \mathrm{~g} / \mathrm{kg} /$ day) for five days before experimentation. Control ani- 


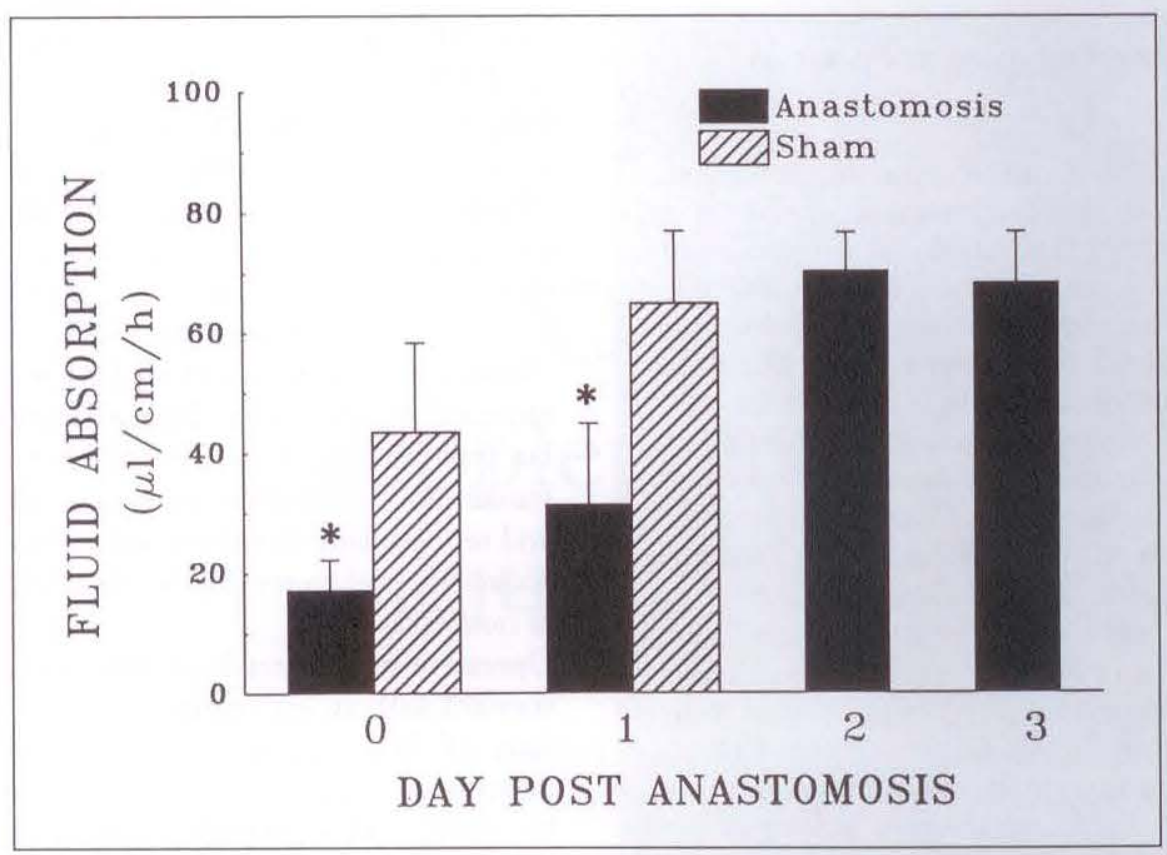

Figure 1) Time course of in vivo fluid absorption at the ileal end-to-end anastomotic site. Results are compared with age-matched, sham-operated controls at zero $(2 \mathrm{~h}$ after anastomosis was performed), and one, two and three days postanastomosis. Ileal anastomosis reduced in vivo fluid absorption on the day of anastomosis (day 0$)$ and one day following anastomosis. Data are mean \pm $\operatorname{SEM}(n=6) .{ }^{*} P<0.05$ relative to sham-operated controls

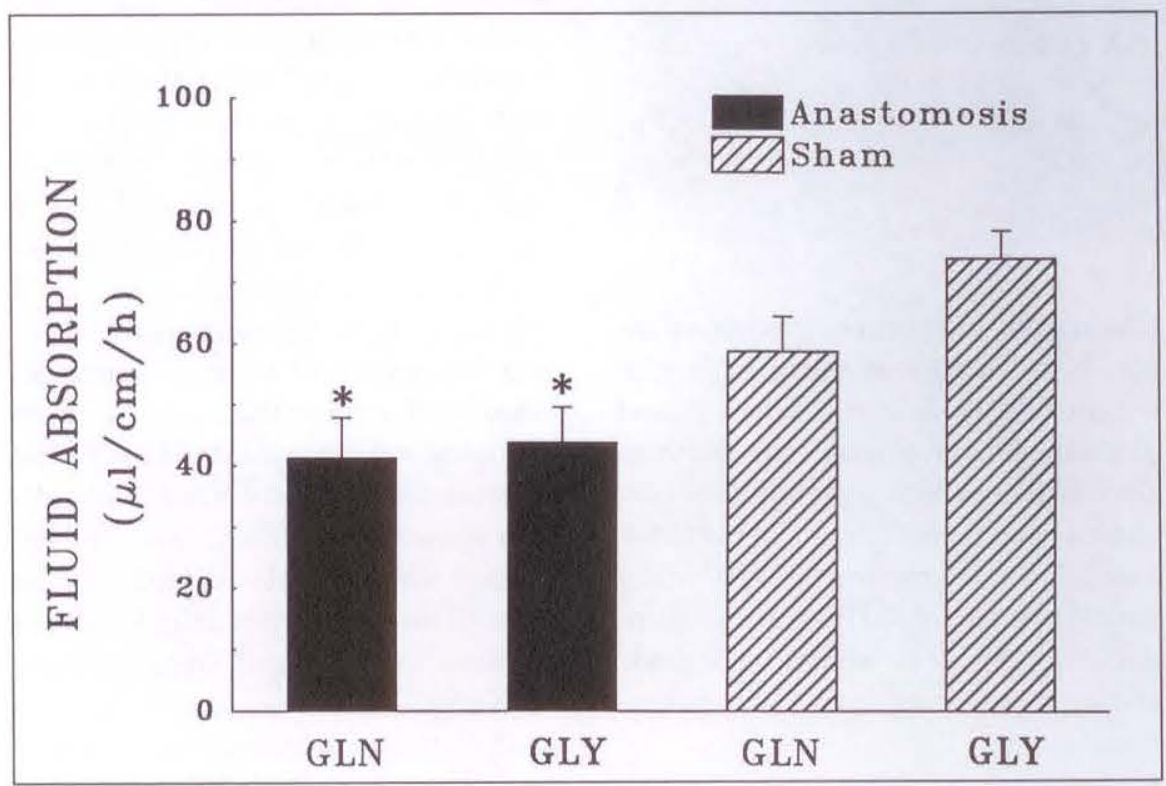

Figure 2) In vivo fluid absorption at the ileal end-to-end anastomotic site one day following anastomosis. Results for glutamine (GLN) - treatment group receiving glutamine - and glycine (GLY) - untreated group receiving no glutamine - dietary supplementation are compared with anastomotic and sham-operated, age-matched controls. Ileal anastomosis lowers in vivo fluid absorption relative to sham-operated controls, and both groups are improved by glutamine dietary supplementation. Data are mean $\pm \operatorname{SEM}(n=6) . * P<0.05$ relative to sham-operated controls

mals received similar amounts of glycine. During this five-day interval, animals were allowed ad libitum access to powdered vital HN (without glutamine or glycine).

\section{MEASUREMENTS}

In vivo absorption loops: In vivo fluid absorption loops were used to assess intestinal function as previously described (16). Briefly, a 10 to $15 \mathrm{~cm}$ segment of ileum (straddling the anastomosis) was isolated by laparotomy. Stool was gently expressed from the segment manually. The empty portion of bowel was tied at each end with a $3-0$ silk tie; care was taken not to interrupt vascular supply. This empty closed loop was filled with $2 \mathrm{~mL}$ of warm saline injected through a 26gauge needle. The abdomen was closed and the animal allowed to recover for $1 \mathrm{~h}$ before sacrifice with a lethal injection of pentobarbitol. The closed loop of intestine was removed intact and the length measured. The segment was weighed with and without the residual luminal saline. Absorption of saline, expressed in $\mu \mathrm{L} / \mathrm{cm}$ intestine $/ \mathrm{h}$, was calculated as an indication of bowel function.

Morphometric assessment: This measurement was done by a researcher blinded to experimental group. Using a computerized videoplan, morphometric parameters were measured and averaged from three separate fields of each section. Villus height, number of villi per centimetre and lamina propria area:perimeter index were evaluated as previously described (17).

DNA content: The DNA content of intestinal homogenates was measured as described by Hindgardner (18). DNA was expressed as mg DNA:mg protein.

Glutaminase activity: Intestinal glutaminase activity reflects enterocyte use of dietary glutamine. Immediately after sacrifice, the rat's intestinal segments were removed, luminal contents were rinsed with ice-cold saline, and the intestine was frozen in liquid nitrogen and stored at $-70^{\circ} \mathrm{C}$. The glutaminase assay was performed as previously described $(19,20)$. Homogenate protein was measured using the Bradford method (21). Glutaminase activity was expressed as $\mu \mathrm{mol} / \mathrm{mg}$ protein $/ \mathrm{h}$.

Location of luminal glutamine: To ensure that glutamine was, indeed, reaching the ileum, the distribution of orally administered glutamine was deter- 


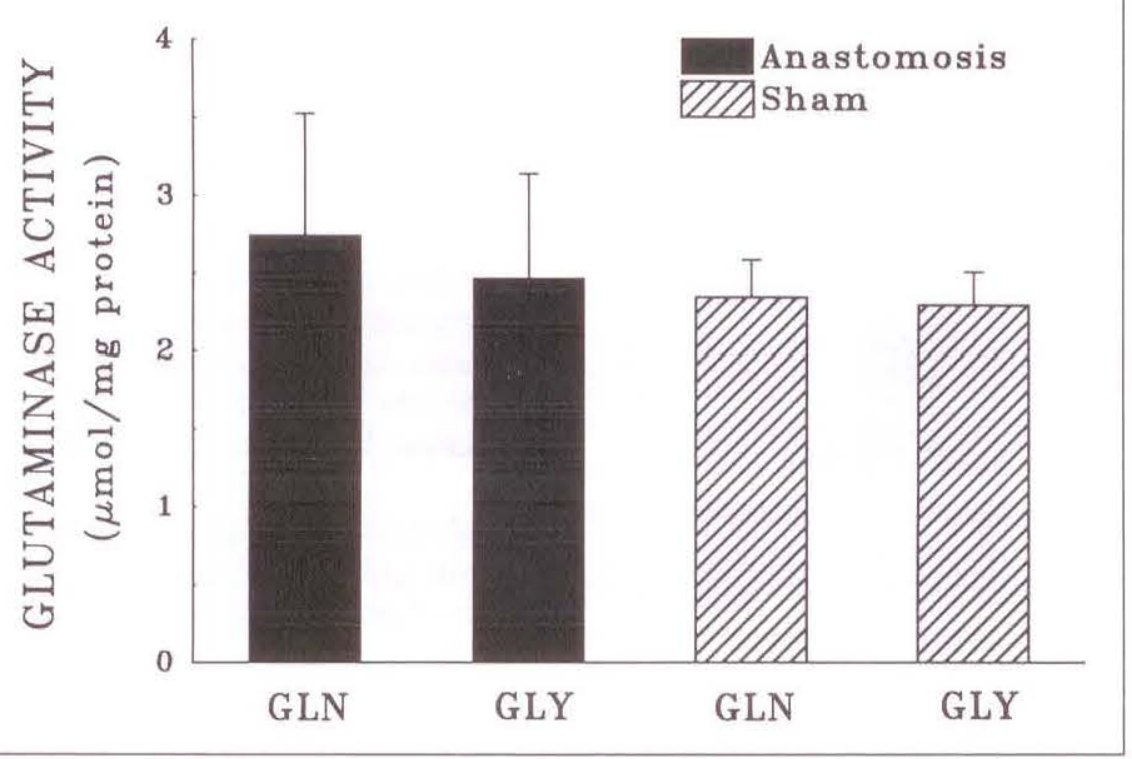

Figure 3) Ileal glutaminase activity one day following ileal end-to-end anastomosis in animals receiving oral glutamine (GLN) - treatment group receiving glutamine - or glycine (GLY) untreated group receiving no glutamine - supplementation. Results for the anastomotic group are compared with sham-operated, age-matched controls. Ileal glutaminase activity is not altered by glutamine or glycine supplementation or by operative procedure. Data are mean $\pm \operatorname{SEM}(n=10)$

mined in a separate group of rats. One gram of ${ }^{14} \mathrm{C}$-labelled glutamine was administered by oral gavage. Animals were sacrificed 1 and $3 \mathrm{~h}$ later and tissue and luminal contents from each $10 \mathrm{~cm}$ segment of intestine, extending from Trietz' ligament to the ileocecal valve, were removed by washing and assayed for radioactivity.

Statistical methods: Results were expressed as mean \pm SEM. Weight gain and food intake were expressed as mean \pm SD. Analysis of variance was used to compare groups and $\mathrm{P}<0.05$ was considered significant.

\section{RESULTS: PART I - ILEAL END-TO-END SURGICAL ANASTOMOTIC MODEL}

Food intake: Daily food intake during the five preoperative days was similar for each group. Glutamine-supplemented animals (treatment group) consumed $14.8 \pm 3.4 \mathrm{~g}$ feed/rat/day $(0.96 \pm$ $0.2 \mathrm{~g}$ glutamine/rat/day and $0.0 \mathrm{~g}$ glycine/rat/day), while those in the glycine-supplemented group (untreated group) ingested $15.1 \pm 3.0 \mathrm{~g}$ feed/rat/day $(0.0 \mathrm{~g}$ glutamine/rat/day and $0.98 \pm 0.19$ g glycine/rat/day). This amount of glutamine is similar to that demonstrated to have had a beneficial influence on previously described intestinal injury models (2-8).

Animal body weight: Animal body weight gain during the preoperative interval was similar for both the glutamine-supplemented animals $(7.5 \pm 2.5$ $\mathrm{g} /$ day) and the glycine-supplemented animals ( $9.6 \pm 1.5 \mathrm{~g} /$ day). Furthermore, this weight gain is similar to agematched animals fed standard rat chow during the same period $(8.3 \pm 2.0$ g/day).

Ileal in vivo fluid absorption: A time course of fluid absorption at the ileal anastomotic site is shown in Figure 1. In vivo fluid absorption at the anastomosis was significantly decreased on day 0 formed) and day 1, relative to sham-operated controls, $\mathrm{P}<0.05$. By day 2 , however, fluid absorption at the ileal anastomotic site had returned to normal. In vivo fluid absorption at the ileal endto-end anastomotic site one day following anastomosis was not altered by oral glutamine supplementation in either anastomotic or sham-operated animals (Figure 2).

Ileal morphometric assessment: In the glutamine- and glycine-supplemented ( $2 \mathrm{~h}$ after the anastomosis was per-
TABLE 1

Distribution of radjoactivity in tissues following oral ${ }^{14} \mathrm{C}$-glutamine administration

\begin{tabular}{lcc}
\hline Tissue & $1 \mathrm{~h}$ & \multicolumn{1}{c}{$3 \mathrm{~h}$} \\
\hline $\begin{array}{l}\text { Stomach } \\
\text { Intestine }\end{array}$ & $49.5 \pm 1.9$ & $5.9 \pm 0.2$ \\
Segment 1 & $3.9 \pm 2.3$ & $1.6 \pm 1.9$ \\
Segment 2 & $2.9 \pm 1.6$ & $2.1 \pm 1.5$ \\
Segment 3 & $3.5 \pm 2.2$ & $0.6 \pm 0.7$ \\
Segment 4 & $3.1 \pm 3.0$ & $0.7 \pm 0.4$ \\
Segment 5 & $4.3 \pm 0.8$ & $1.1 \pm 1.8$ \\
Segment 6 & $2.9 \pm 1.4$ & $0.5 \pm 0.8$ \\
Segment 7 & $3.2 \pm 0.4$ & $0.7 \pm 1.0$ \\
Segment 8 & $3.2 \pm 1.2$ & $0.7 \pm 0.6$ \\
Segment 9 & $2.0 \pm 1.9$ & $1.2 \pm 1.1$ \\
Segment 10 & $0.2 \pm 0.9$ & $1.0 \pm 0.9$ \\
Liver & $11.0 \pm 1.1$ & $4.8 \pm 1.6$ \\
Pancreas & 0 & 0 \\
Spleen & $0.3 \pm 0.3$ & $0.3 \pm 0.5$ \\
Kidneys & $0.8 \pm 0.9$ & $1.4 \pm 0.8$ \\
Heart & $0.1 \pm 0.3$ & $0.1 \pm 0.4$ \\
Blood & $0.4 \pm 0.4$ & $0.5 \pm 0.6$ \\
\hline Yield* & 91.3 & 23.0 \\
\hline To & &
\end{tabular}

To ensure adequate intraluminal ileal concentrations of glutamine in the experimental group, glutamine was administered by oral gavage 1 g every $12 \mathrm{~h}$ ( 2 g/day, approximately $8 \mathrm{~g} / \mathrm{kg} /$ day) for five days before experimentation. Values are mean \pm SEM $(n=4)$ expressed as a percentage of the administered dose recovered from tissue. Segments 1 to 10 represent 10 cm increments; segment 1 begins at Trietz' ligament and segment 10 ends at the lleocecal valve. "Proportion of administered radioactivity recovered from sum of tissues analyzed

groups no significant differences in ileal villus height $(285 \pm 14 \mu \mathrm{m}$ versus $272 \pm 16 \mu \mathrm{m}$, respectively), number of villi/cm $(76.6 \pm 7.6$ versus $73.0 \pm 10.8$, respectively) or lamina propria area:perimeter index $(19.4 \pm 1.68$ versus $17.5 \pm 4.3$, respectively) were noted. As well, these ileal morphometric parameters did not change between sham-operated and anastomotic groups.

Ileal glutaminase activity: Ileal glutaminase activity, as a measure of glutamine use by the enterocyte, was not significantly altered by glutamine or glycine supplementation or by the operative procedure (Figure 3 ).

Location of luminal glutamine: To ensure that glutamine was reaching the ileum, ${ }^{14} \mathrm{C}$-labelled glutamine was administered and its progress through the intestine mapped. As shown in Table 1, glutamine had emptied from the stomach by $3 \mathrm{~h}$. Furthermore, glutamine was 


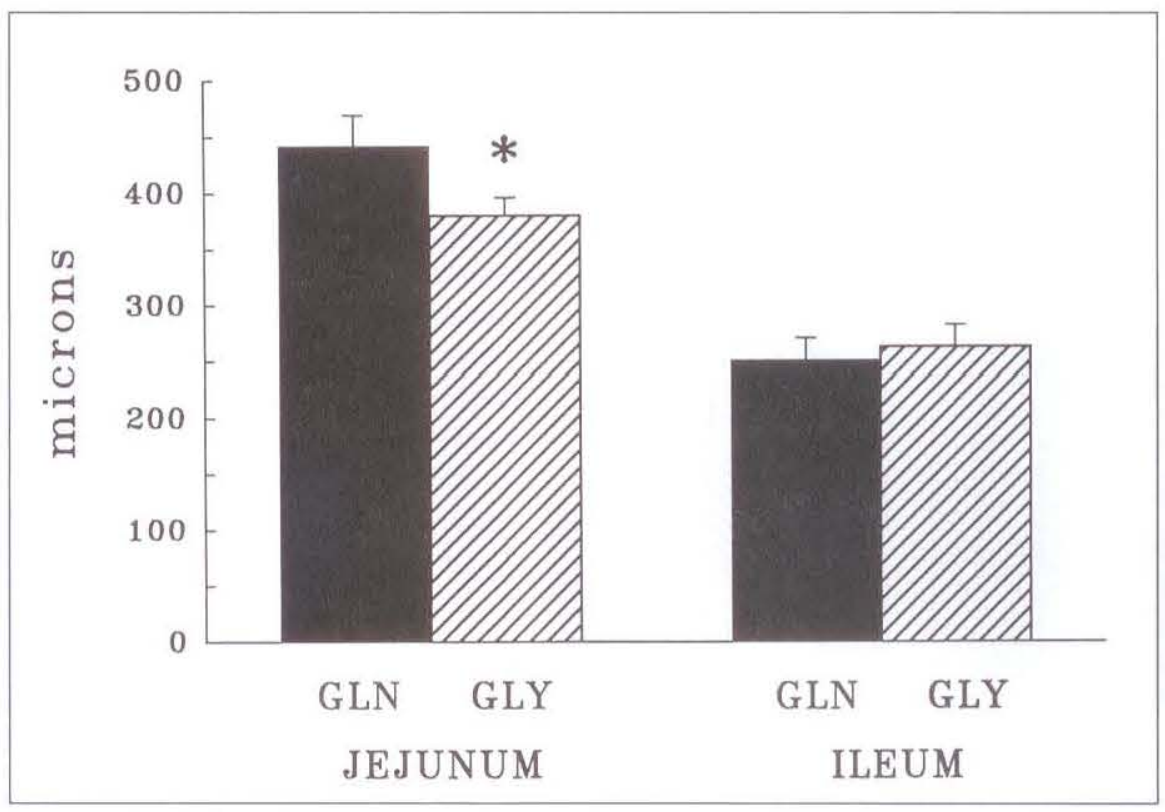

Figure 4) Villus height in jejunum and ileum of the nonsurgical model receiving oral glutamine $(G L N)$ - treatment group receiving glutamine - or glycine $(G L Y)$ - untreated group receiving no glutamine-supplementation. Villus height increased in the jejunum, but not the ileum, of glutaminesupplemented animals. Data are mean $\pm \operatorname{SEM}(n=6)$. ${ }^{*} P<0.05$ relative to GLY

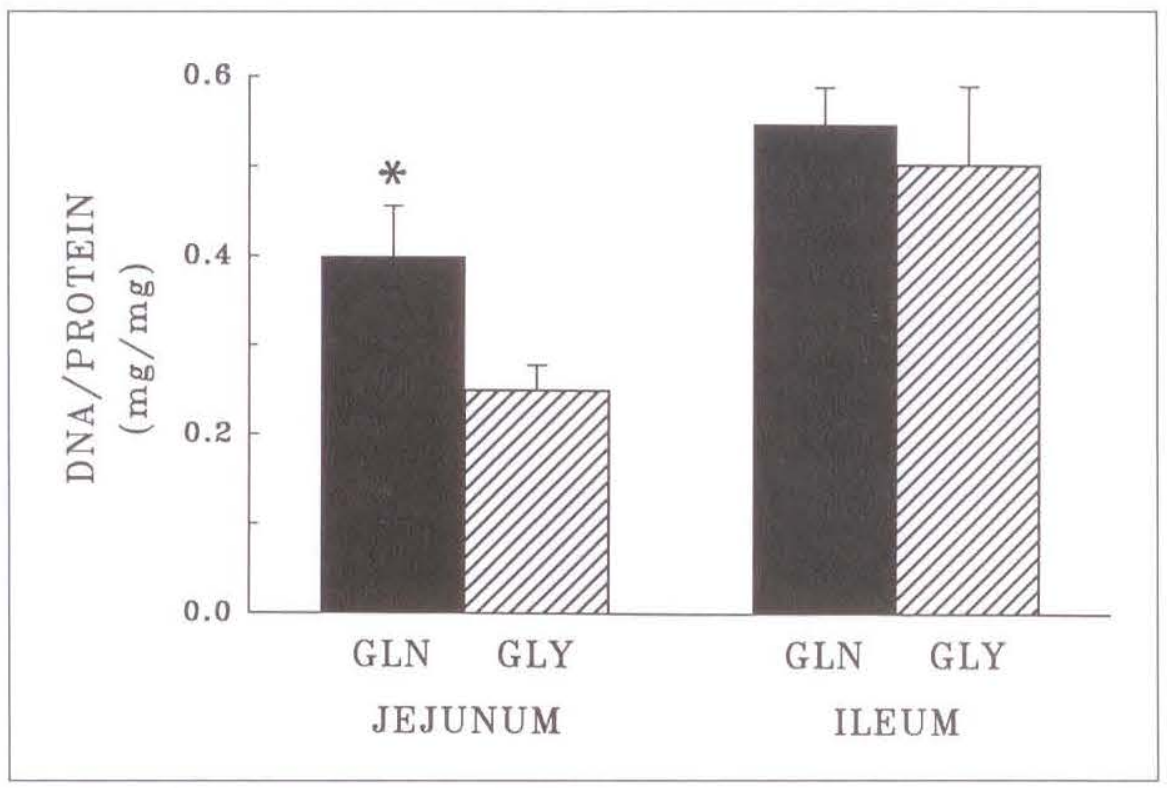

Figure 5) DNA:protein ratio in jejunal and ileal mucosal homogenates of the nonsurgical model receiving oral glutamine (GLN) - treatment group receiving glutamine - or glycine (GLY) untreated group receiving no glutamine - supplementation. There is a significant increase in the DNA:protein ratio in the jejunum, but not ileum, of glutamine-supplemented animals. Data are mean $\pm \operatorname{SEM}(n=6) . * P<0.02$ relative to $G L Y$

equally distributed between 'Trietz' ligament and the ileal-cecal valve.

\section{RESULTS: PART II - NONSURGICAL MODEL}

Because in vivo fluid absorption, morphometric measurements and glu- taminase activity did not benefit from oral glutamine supplementation in the surgical ileal end-to-end anastomotic model despite glutamine being delivered to the ileum, the authors investigated the possibility of a regional difference in the ability of the small intestine to respond to glutamine.

Ileal in vivo fluid absorption: Dietary supplementation with glutamine (treatment group receiving glutamine) or glycine (untreated group receiving no glutamine) did not alter basal jejunal $(156 \pm 8 \mu \mathrm{L} / \mathrm{cm} / \mathrm{h})$ or ileal $(95 \pm 7)$ fluid absorption in the nonsurgical model relative to levels seen in chow-fed animals $(149 \pm 11 \mu \mathrm{L} / \mathrm{cm} / \mathrm{h}$ and $102 \pm 12$, respectively).

Morphometric assessment: Villus height significantly $(P<0.05)$ increased in the jejunum of glutamine-supplemented animals (Figure 4). In contrast, the ileum demonstrated no increase in villus height with glutamine relative to glycine supplementation.

DNA:protein ratio: To confirm that the increased jejunal villus height was due to an increased number of enterocytes, DNA and protein levels in jejunal and ileal mucosal homogenates were measured. There was a significant $(\mathrm{P}<0.02)$ increase in the mg DNA:mg protein ratio in the jejunum of glutamine-supplemented animals. Once again, the ileum did not respond to glutamine supplementation (Figure 5).

Glutaminase activity: As shown in Figure 6 , glutaminase activity increased in the jejunum of the glutamine-supplemented group. In contrast, glutaminase activity in the ileum was not enhanced by glutamine.

\section{DISCUSSION}

A number of studies have investigated the effects of parenterally and enterally administered glutamine on both normal and injured intestine. The majority of these studies confirmed the beneficial effects on the jejunum $(1-8$, 10-13,22-24), whereas the effects of glutamine on the ileum have been less well described $(9,25)$. Our study thus examined the effects of oral glutamine supplementation on the ileum in both a surgical (ileal end-to-end anastomosis) and a nonsurgical model. Orally administered glutamine is absorbed in the proximal jejunum, where $85 \%$ is transformed before entry into the systemic circulation $(26,27)$. Studies done on rats have shown that the rates of glutamine use by the jejunum are simi- 
lar whether glutamine is derived from arterial blood or gut lumen (5). Nevertheless, the importance of an orally administered source of glutamine is suggested by the fact that rats deprived of it develop intestinal hypoplasia $(28,29)$.

Intestinal absorptive function around the ileal end-to-end surgical anastomosis was impaired significantly on days 0 and 1 postanastomosis as assessed by in vivo fluid absorption. While it is not surprising that intestinal fluid and electrolyte absorptive function should be diminished at the site of intestinal anastomosis, we are unaware of this decrease having been previously described. While the mechanism leading to this fluid absorptive dysfunction has not been examined, it likely relates to local ischemia and subsequent free radical or cytokine release. We have previously shown that alteration in in vivo intestinal fluid absorption is a sensitive measure of mucosal injury. Indeed, intestinal transport abnormalities will persist for days after gross macroscopic and morphometric appearance have returned to normal (16).

Our experiment showed that oral glutamine supplementation did not accelerate healing of the fluid absorptive impairment around an ileal end-to-end anastomosis. Furthermore, in this surgical model, glutamine supplementation did not enhance ileal villus morphometric measurements or the level of ileal glutaminase activity; this raises the possibility that adequate amounts of glutamine may not have been presented to the ileum in this model. The total quantity of glutamine $(0.96 \pm 0.2$ $\mathrm{g} / \mathrm{rat} /$ day) consumed was likely adequate as it was similar to the amount shown to be beneficial in other studies $(3,9-13,30)$. Furthermore, our studies using ${ }^{14} \mathrm{C}$-labelled glutamine as a marker confirmed that glutamine was present in the ileal lumen (Table 1).

Although glutamine supplementation has been shown to enhance ileal morphometric measurements, this enhancement occurred in conjunction with a $60 \%$ small bowel resection (31) or in normal intestine from rats supplemented with parenteral glutamine

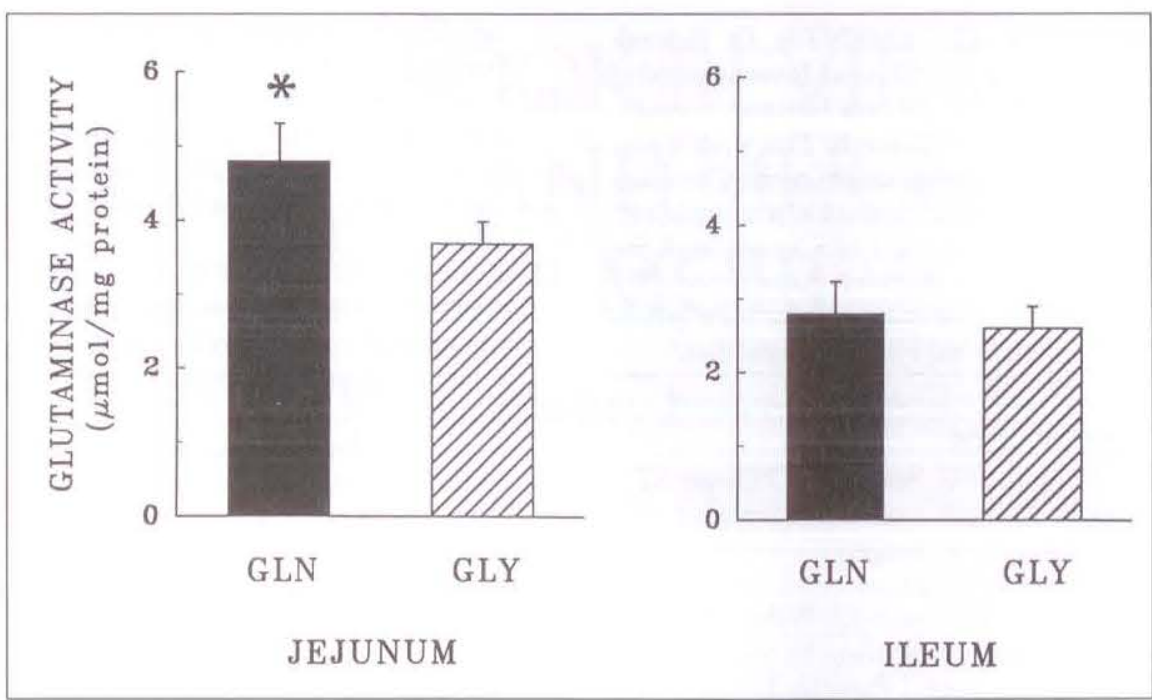

Figure 6) Glutaminase activity in jejunum and ileum of the nonsurgical model receiving oral glutamine (GLN) - treatment group receiving glutamine - or glycine (GLY) - untreated group receiving no glutamine - supplementation. Glutaminase activity is increased in the jejunum, but not ileum, of the glutamine-supplemented group. Data are mean $\pm \operatorname{SEM}(n=4)$. $* P<0.05$ relative to GLY

(25). These results are unlikely to be a consequence of increased glutamine delivery to the ileum because our study demonstrated no evidence of enhanced ileal morphometric measurements even though equal amounts of glutamine were delivered to the jejunum and ileum following oral administration. It remains to be determined whether a beneficial effect of glutamine on the ileum requires an increased duration of glutamine contact with the intestine or the presence of specific binary or pancreatic products. Incontinuity jejunum in dogs has higher glutaminase activity and glutamine transport levels than those seen in an excluded jejunal limb in the same animals, a difference likely due to the presence of luminal constituents (32).

These observations, and our own negative ileal results, prompted us to study the effects of oral glutamine supplementation in a nonsurgical model to determine whether the ileum is capable of responding to oral glutamine. This part of the study examined the effects of glutamine, compared with glycine (control), in both ileum and jejunum. Our results were similar to those of Salloum et al (24), and demonstrated that glutamine supplementation enhanced jejunal morphometric measurements,
DNA content and glutaminase activity. In contrast, glutamine had no positive effect on paired ileal measurements in the same animals. These negative results occurred despite radiolabelled demonstrations that intraluminal glutamine reached the ileum in amounts similar to that seen in jejunum (Table 1). Glutamine absorbed in the proximal small intestine is transformed in the jejunal enterocyte, and this early transformation may alter the distal small bowel response to oral glutamine. An alternate explanation is that the ileum is less sensitive than the jejunum to the effects of glutamine. In support of this hypothesis, Tamada et al (33) recently demonstrated that the parenteral administration of the dipeptide alanyl-glutamine enhanced villus height in the jejunum but not the ileum. The ileum may thus require 'jejunalization' by an enteral nutrient stream to become as sensitive to glutamine as the jejunum.

\section{CONCLUSIONS}

The beneficial effects of oral glutamine supplementation may be limited to the proximal small intestine. Further studies will be necessary to clarify the mechanisms responsible for the apparent nonresponse of the ileum to oral glutamine. 
ACKNOWLEDGEMENTS: Dr Fedorak is a recipient of a Clinical Investigatorship Award from the Alberta Heritage Foundation for Medical Research. This work is supported by research grants from the Canadian Foundation for Ileitis and Colitis, the Medical Research Council of Canada and the Edmonton Fire Fighters' Association. We thank Ross Laboratories Inc for their generous supply of vital HN elemental diet.

\section{REFERENCES}

1. Wilmore DW, Smith RJ, O'Dwyer ST, et al. The gut: a central organ after surgical stress. Surgery 1988;104:917-23.

2. Souba WW, Smith RJ, Wilmore DW. Glutamine metabolism by the intestinal tract. J Parenter Enteral Nutr 1985;9:608-17.

3. Souba WW. The gut as a nitrogen-processing organ in the metabolic response to critical illness. Nutr Suppl Serv 1988;8:15-22.

4. Herskowitz K, Souba WW. Intestinal glutamine metabolism during critical illness: a surgical perspective. Nutrition 1990;6:199-206.

5. Windmueller HG, Spaeth AE. Uptake and metabolism of plasma glutamine by the small intestine. J Biol Chem 1974;249:5070-9

6. Aikawa T, Matsutaka H, Yamamoto $\mathrm{H}$, et al. Gluconeogensis and amino acid metabolism II. Inter-organal relations and roles of glutamine and alanine in the amino metabolism of fasted rats. Arch Surg 1973;74:1003-19.

7. Hanson PJ, Parsons DS. Metabolism and transport of glutamine and glucose in vascularly perfused rat small intestine. J Biochem 1977;166:509-19.

8. Windmueller HG, Spaeth AE. Identification of ketone bodies and glutamine as the major respiratory fuels in vivo for post absorptive rat small intestine. J Biol Chem 1978;253:69-76.

9. Jacobs DO, Evans AE, O'Dwyer ST, et al. Disparate effects of 5-fluorouracil on the ileum and colon of enterally fed rats with protection by dietary glutamine. Surg Forum 1987;38:45-7.

10. Fox AD, Kripke SA, Berman JM, et al. Reduction of the severity of enterocolitis by glutamine- supplemented enteral diets. Surg Forum 1987;38:43-4.

11. Fox AD, Kripke SA, De Paula J, et al Effect of a glutamine-supplemented enteral diet on inethotrexate-induced enterocolitis. J Parenter Enteral Nutr 1988; 12:325-31.

12. Klimberg VS, Souba WW, Dolson JD, et al. Prophylactic glutamine protects the intestinal mucosa from radiation injury. Cancer 1988;66:62-8.

13. Klimberg VS, Salloum RM, Kasper M, et al. Oral glutamine accelerates healing of the small intestine and improves outcome after whole abdominal radiation. Arch Surg 1990;125:1040-5.

14. Klimberg VS, Souba WW, Dolson DJ, et al. Prophylactic glutamine protects the intestinal mucosa from radiation injury. Cancer 1990;66:62-8.

15. Ziegler TR, Young LS, Benfell K, et al. Clinical and metabolic efficacy of glutamine-supplemented parenteral nutrition after bone marrow transplantation. Ann Intern Med 1992;116:821-8.

16. Fedorak RN, Empey LR, Macarthur C, et al. Misoprostol provides a colonic mucosal protective effect during acetic acid-induced colitis in rats. Gastroenterology 1990;98:615-25.

17. Juby LD, Dixon MF, Axon ATR. Abnormal intestinal permeability and jejunal morphometry. J Clin Pathol 1987;40:714-8.

18. Hindgardner RT. An improved fluorometric assay for DNA. Annal Biochem 1971;39:197-201.

19. Pinkus LM, Windmueller HG. Phosphate-dependent glutaminase of small intestine: Localization and role in intestinal glutamine metabolism. Arch Biochem Biophys 1977;182:506-17.

20. Curthoys NP, Lowry OH. The distribution of glutaminase isoenzymes in the various structures of the nephron in normal, acidotic and alkalotic rat kidney. J Biol Chem 1973;248:162-8.

21. Bradford MM. A rapid and sensitive method for the quantitation of microgram quantities of protein utilizing the principle of dye binding. Annal Biochem 1976;72:248-54.

22. Grant JP, Snyder PJ. Use of
L-glutamine in total parenteral nutrition. J Surg Res 1988;44:506-13.

23. O'Dwyer ST, Smith RJ, Hwang TL, et al. Maintenance of small bowel mucosa with glutamine-enriched parenteral nutrition. J Parenter Enteral Nutr 1989;13:579-85.

24. Salloum RM, Souba WW, Klimberg $\mathrm{VS}$, et al. Glutamine is superior to glutamate in supporting gut metabolism, stimulating intestinal glutaminase activity, and preventing bacterial translocation. Surg Forum 1989;40:6-8.

25. Jacobs DO, Evans DA, Mealy K, O'Dwyer ST, Smith RJ, Wilmore DW. Combined effects of glutamine and epidermal growth factor on the rat intestine. Surgery 1988;104:358-64.

26. Dechelotte P, Darmaun D, Rongier M, et al. Absorption and metabolic effects of enterally administered glutamine in humans. Am J Physiol 1991;260:G677-82.

27. Ziegler TR, Brown E, Smith RJ, et al. Metabolism of oral and iv glutamine in healthy humans. FASEB J 1989;3:A1248.

28. Hwang TL, O'Dwyer ST, Smith RJ, et al. Preservation of small bowel mucosa using glutamine-enriched parenteral nutrition. Surg Forum 1986;37:56-8.

29. Plattel C, McCauley R, McCulloch R, et al. Influence of glutamine and branched chain amino acids on the jejunal atrophy associated with parenteral nutrition. J Gastroenterol Hepatol 1991;6:345-9.

30. Souba WW, Klimberg VS, Hautamaki $\mathrm{RD}$, et al. Oral glutamine reduces bacterial translocation following abdominal radiation. J Surg Res 1990;48:1-5.

31. Smith RJ, Wilmore DW. Glutamine nutrition requirements. J Parenter Enteral Nutr 1990;14(Suppl):94S-9S.

32. Salloum RM, Stevens BR, Souba WW. Adaptive regulation of brush-border amino acid transport in a chronic excluded jejunal limb. Am J Physiol 1991;261:G22-7.

33. Tamada $H$, Nezu R, Imamura I, et al. The dipeptide alanyl-glutamine prevents intestinal mucosal atrophy in parenterally fed rats. J Parenter Enteral Nutr 1992;16:110-6. 


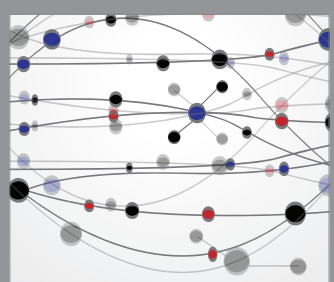

The Scientific World Journal
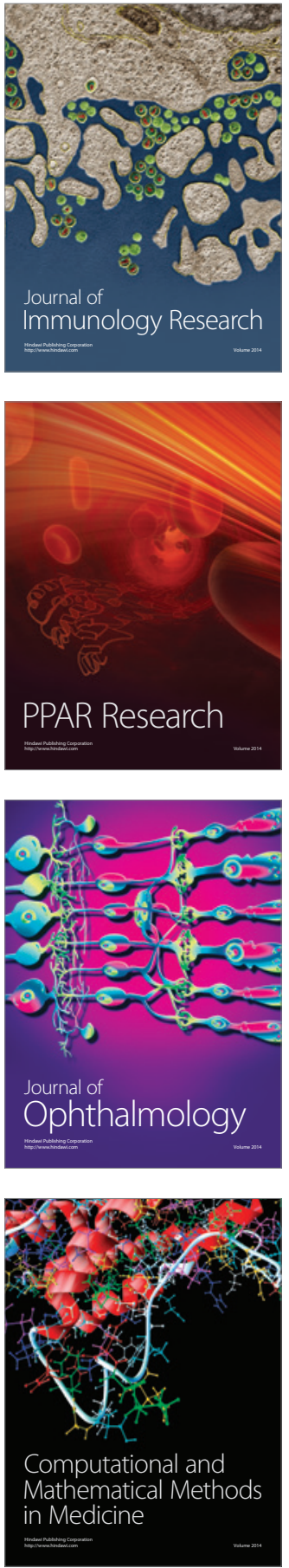

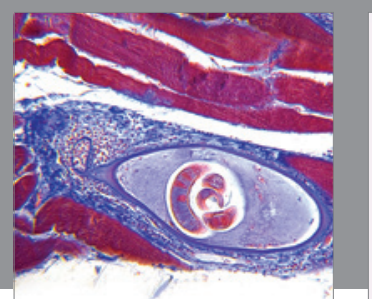

Gastroenterology Research and Practice

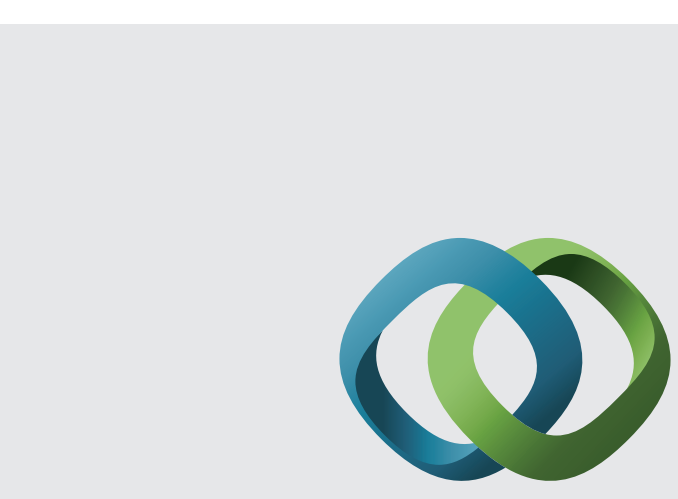

\section{Hindawi}

Submit your manuscripts at

http://www.hindawi.com
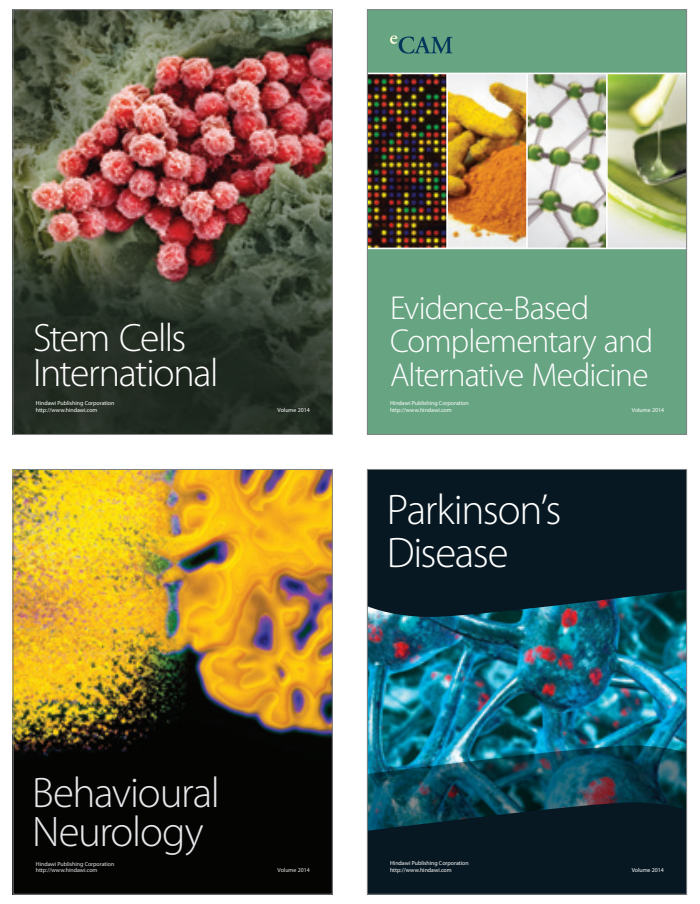
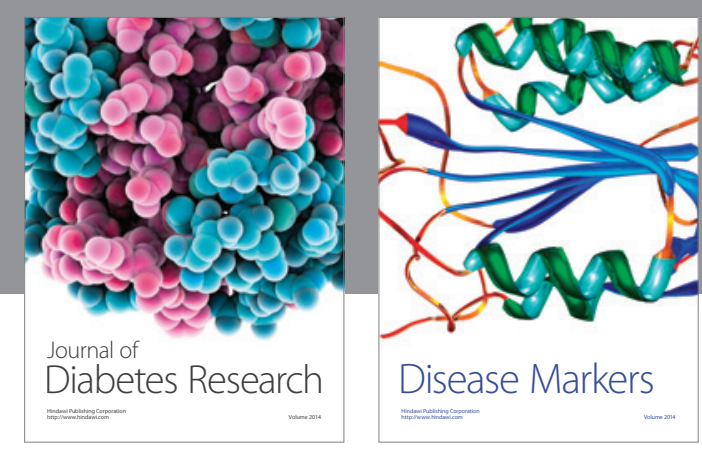

Disease Markers
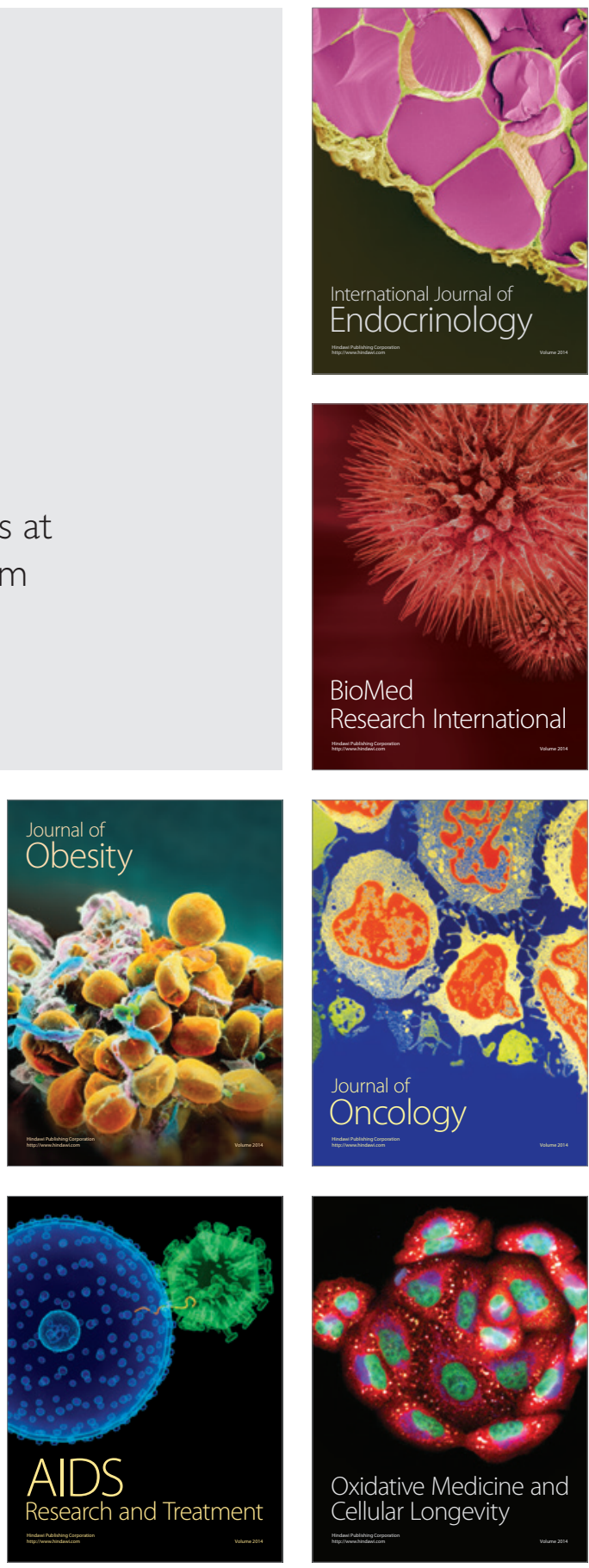